\title{
Effects of private and public health expenditure on health outcomes among countries with different health care systems: 2000 and 2014
}

\author{
Pouran Raeesi ${ }^{1}$, Touraj Harati-Khalilabad ${ }^{* 2}$, Aziz Rezapour ${ }^{3}$, Samad Azari ${ }^{2}$, Javad Javan-Noughabi ${ }^{4}$ \\ Received: 15 Feb 2017 \\ Published: 1 May 2018
}

\section{Abstract}

Background: In the recent decades, most studies have paid more attention to community expenditures in health sector and health outcomes. This study provides econometric evidence linking countries' health expenditures to 3 health outcomes: (1) infant mortality, (2) under 5 mortality and (3) life expectancy within 4 different health care systems.

Methods: In this study, we used the econometric method to estimate the effect of health expenditure on health status. Panel data were collected and grouped for 25 countries according to the health care system over 15 years (2000-2015). The random effects model was selected over the fixed effects model based on the Hausman test to assess the effect of different factors on the 3 mentioned health outcomes.

Results: A significant relationship was found between health expenditures and health indicators. The effect of private health expenditures on health outcomes in countries with mixed health financing system and traditional sickness fund insurance was higher than public expenditures. Also, after comparing the results between different health care systems, we found that the effect of health expenditure on the health outcome in countries with national health system (NHS) was more than other health care systems.

Conclusion: To improve health status, health policymakers should focus on the factors that lie inside the health care system. Therefore, since private and public health expenditures have different effects on health outcomes in each health care system, countries should choose an optimal combination of private and public health expenditures.

Keywords: Health expenditures, Health outcomes, Healthcare system, Panel data method

Copyright $\odot$ Iran University of Medical Sciences

Cite this article as: Raeesi P, Harati-Khalilabad T, Rezapour A, Azari S, Javan-Noughabi J. Effects of private and public health expenditure on health outcomes among countries with different health care systems: 2000 and 2014. Med J Islam Repub Iran. 2018(1 May);32:35. https://doi.org/10.14196/mjiri.32.35

\section{Introduction}

Nowadays, health is considered as one of the substantial tools and play an important role in development process (1). Population health, as the consequence of the health sector, is affected by many factors such as economics and social conditions, inputs of health sector, and type of health care systems. Nevertheless, the relationship between these factors and consequences of the health sector is a part of requirements in any country. In fact, a country has more effective health care system if it has better health outcomes than countries with similar level of health resources (2).

Health outcomes reveal their impact on human capital in many ways. Before introduction of human capital theory, just physical capital dimension was taken into account in

1. Department of Health Management, School of Health Management and Information Sciences, Iran University of Medical Sciences, Tehran, Iran.

2. Department of Health Economics, School of Health Management and Information Science, Iran University of Medical Sciences, Tehran, Iran.

${ }^{3 .}$ Health Management and Economics Research Center, Iran University of Medical Sciences, Tehran, Iran.

4. Dezful University of Medical Sciences, Dezful, Iran.

$\uparrow$ What is "already known" in this topic:

Health care systems and their related health expenditures are an important factor in improving health outcomes.

\section{$\rightarrow$ What this article adds:}

In countries with national health care system, the effect of public health expenditures on health outcomes (life expectancy, infant mortality rate, and under 5 mortality rate) was $0.44,-0.31$, and 0.41 , respectively. Public health expenditures have the biggest impact on health outcomes in national health care systems compared to other health care systems. Also, private health expenditures have the biggest impact on health outcomes in countries with traditional sickness insurance compared to other health care systems. 
consideration of the human capital; however, after this theory was established in 1960, health outcomes and their impact on the health capital have been more taken into consideration. In other words, economists have put special emphasis on the roles of human capital in the development process since $1960(3)$.

In this regard, various factors, such as the health care system (the rate of proportion of health expenditure), lifestyle, environment, political system, and social and cultural conditions that affect the health of humans have been more considered (4)

To achieve the appropriate level of development, a fair amount of expenditure should be always spent on the health care sector. Based on this mechanism, health expenditures increase health capital, and consequently increase human capital (5).

Based on theoretical principles, increase in human capital stock will increase the speed of return on investment in human resources, and finally will increase the total investment of economy. In other words, this increase in the investment of economy is due to the increased resource utilization and an increase in life expectancy, with a positive return on investment in the community. Therefore, increased life expectancy will increase savings and investment in the private sector, improving the economic conditions of the country; this improvement will improve the health indicators by cycle-shape process (6).

According to different health care systems, the amount and type of health expenditure are different in the health care systems of countries (7). Total health expenditure may be provided by the public sector or social security. Also, in some systems, health expenditure may be provided by the private sector and the individuals in the form of out- ofpocket payments. In some health care systems, the financing methods are not dominant and there are various ways of financing and service delivery (8). According to the health consequences of these countries, there are differences in the health indicators among this group of systems. This in turn reflects the difference between the efficiency of health expenditure in countries with different health care systems. For instance, according to the report of the World Health Organization (WHO) and the World Bank in 2014, the United States is a country with the highest health expenditure by spending $17.1 \%$ of the gross domestic product (GDP) in the health sector, while Singapore only spends $9.4 \%$ of GDP in the health sector and has a better situation (ranked second) than the United States (ranked 44) in the fields of health indicators such as infant mortality rates. This indicates the difference between the efficiency of health expenditure in health care systems of both countries (9).
In this regard, numerous studies have investigated the impact of health expenditure on health outcomes, and most of these studies have utilized such indicators as life expectancy at birth, infant mortality rate, under 5 mortality rate of children, etc.

Swaroop and Rajkyman (10), Kim and Lane (11), Akinci et al. (12), Jaba et al. (2), Elola et al. (13), Novignon et al. (14), Makuta and O'Hare (15), and Anyanwu and Erhijakpor (16) have studied the relationship between health expenditures and health outcomes. A number of these studies show that health expenditures are correlated with health outcomes with a high coefficient.

Therefore, we can investigate the impact of health expenditure on health indices within the framework of countries with different health systems according to the increasing importance of health in development of countries and its impact on individual efficiency and according to the increase in the financial burden of financing in the health sector in different countries. The strengths of this study include the separation of health expenditure and the use of other explanatory variables within the framework of the model. Furthermore, classifying countries based on health systems and the studied relationships within each category of systems and comparing the existing relationships between each health system were the milestones in conducting this study.

\section{Methods}

The study pooled cross-sectional and annual time series data from 2000 to 2014 for 25 countries with different health care systems. This study used data from the World Bank and World Development Indicators (WDI) (17). Analysis was performed using Eviews 8 software package.

This study used the study by Karimi et al. (18) and Senaratne (19) to classify the countries based on health care system type. Table 1 presents the names of countries and also their health care system type.

The following model can be investigated in 4 groups of countries according to the review of previous studies on factors affecting health consequences and consideration of theoretical principles and theoretical models. The general framework of this study started through the following identified health model:

$$
Y_{i t}=X_{i t} \beta+\mathcal{E}_{t}, t=1 \ldots \ldots \ldots . T x 1, \mathcal{E}_{t}=\mu w+v
$$

In this model, $Y_{i t}$ is a vector of dependent variables in country $\mathrm{i}$ at the time $\mathrm{t}$; and $x_{\text {" }}$ is a vector of independent and exogenous variables. $\beta$ is a vector of coefficients. $\mathcal{E}_{t}$ is also a vector of random errors. The second equation

Table 1. Classification of countries included in the study based on their health care systems

\begin{tabular}{lcc}
\hline Health care system & Description & countries \\
\hline National Health Insurance System & Health insurance systems are presented in na- & Canada, Finland, Norway, Spain, and Sweden \\
tional level. & $\begin{array}{c}\text { Fundamentally, a private insurance market ap- } \\
\text { proach with a state subside } \\
\text { State provides health care. }\end{array}$ & $\begin{array}{c}\text { Austria, Belgium, France, Luxembourg, Netherlands } \\
\text { Germany }\end{array}$ \\
National Health Services & $\begin{array}{c}\text { United Kingdom, Denmark, Greece, Italy, New Zea- } \\
\text { land, Portugal, Turkey }\end{array}$ \\
Mixed systems & $\begin{array}{c}\text { They contain elements of both traditional sick- } \\
\text { ness insurance and national health coverage. }\end{array}$ & $\begin{array}{c}\text { Australia, Iceland, Ireland, Japan, Iran, Switzerland, } \\
\text { United States of America }\end{array}$ \\
\hline
\end{tabular}


consists of 2 residuals of error terms and temporal variability; in this equation, the error term has the spatial correlation with weight matrix $\mathcal{W}$ and the spatial autocorrelation with parameter $\mu$ (14). Therefore, for the purposes of this study, the following econometrics models specifications were estimated in 4 groups of countries with different health care systems (16).

$L E_{i t}=\alpha_{i}+\beta_{1} P u H E_{i t}+\beta_{2} P r H E_{i t}+\beta_{3} Y_{i t}+\beta_{4} P H Y_{i t}+$ $\varepsilon_{i t}(1)$

(2) $I M R_{i t}=\alpha_{i}+\beta_{1} P u H E_{i t}+\beta_{2} P r H E_{i t}+\beta_{3} Y_{i t}+\beta_{4}$ $P H Y_{i t}+\varepsilon_{i t}$

(3) $U M R 5_{i t}=\alpha_{i}+\beta_{1} P u H E_{i t}+\beta_{2} P r H E_{i t}+\beta_{3} Y_{i t}+\beta_{4}$ PHY $Y_{i t}+\varepsilon_{i t}$

Where variables life expectancy at birth (LE), infant mortality rate (IMR), and the under 5 mortality rate (UMR5) are dependent variables. These are commonly used proxies because these variables have higher accuracy and are broader criteria for indicating health status (16). Also, public health expenditure, as a percentage of GDP (PuHE), private health expenditure, as a percentage of GDP (PrHE), real per capita income (Y), and per capita number of physicians per 1000 population (PHY) are the independent and control variables.

In this model, $\mathrm{i}$ identifies a country and $\mathrm{t}$ time period. In this model, $\varepsilon$ refers to the error term. Furthermore, $\alpha$ is time invariant and captures country-specific effect that was not included in the model and refers to the effects on the health outcomes. The estimated effect of independent variables on health outcomes is expressed by the $\beta$ coefficient.

In this study, the multivariate regression model is utilized to investigate the effects of studied variables on health. To estimate the models, in first steps to prevent spurious regression and problem, stationary tests had to be performed. Moreover, Im-Pesaran and Shin stationary tests were used.

In the next steps, using the generalized least squares method (GLS) and the ordinary least squares (OLS), we investigated the fixed and random effects in 3 models.

Chow test was used to choose from integrated or fixed effects model. Also, Hausman test was used to select the best model between the fixed and random effects models.

Baltagi et al. (20) believe that the use of model with random effects is more appropriate as long as there is not any time relationship between the error and residual terms. Furthermore, according to Cameron and Trivedi (21), the use of model with fixed effects is more appropriate to control the effects of removing the endogenous variables that should exist in the model, but they are excluded from the model.

With respect to the target countries in this study, we collected the whole data from the authentic and concentrated sources to reduce the bias of data collection.

\section{Results}

In the first step, an appropriate model should be selected to estimate a panel model. Therefore, Chow test (pooled least squares or least squares dummy variables (LSDV)) and Hausman test (selection of model by random or fixed effects) were used to select the model for each group of countries with same health care system.

According to the results of Chow and Hausman specification test for models 1,2 , and 3 in different countries, the results sindicated that the random effects model was favoured over the fixed effects model.

We analyzed 3 separate models because our study included 3 dependent variables in 4 groups of countries with different health care system, and results are demonstrated in Tables 2 to 5, respectively. The dependent variables of models 1, 2, and 3 are life expectancy, infant mortality rate, and under 5 mortality rate, respectively.

\section{Estimation of results in countries with national health} insurance system

Based on model 1, there was a positive relationship between public and private health expenditure and life expectancy. Specifically, 1 unit increase in public and private health expenditure increases life expectancy by 0.08 and 0.021 units, respectively.

Furthermore, 1 unit increase in per capita income and per capita number of physicians increases 4.73 and 8.001 units, respectively. Moreover, according to the models 2 and 3,

Table 2. Estimated results in countries with national health insurance systems

\begin{tabular}{|c|c|c|c|}
\hline \multirow{2}{*}{ Variable } & Model(1) & $\operatorname{Model}(2)$ & Model(3) \\
\hline & Life expectancy & Infant mortality rate & Under 5 mortality rate \\
\hline $\mathrm{C}$ & $32.58(0.01)^{*}$ & $263.77(<0.001)$ & $258.88(0.00)$ \\
\hline Public health expenditure & $0.08(0.04)$ & $-0.03(0.019)$ & $-0.03(0.029)$ \\
\hline Private health expenditure & $0.021(0.024)$ & $-0.02(0.5)$ & $-0.014(0.012)$ \\
\hline Real per capita income & $4.73(<0.001)$ & $-2.08(<0.001)$ & $-6.17(<0.001)$ \\
\hline number of per capita physician & $8.001(0.004)$ & $-10.06(<0.001)$ & $-2.56(0.00)$ \\
\hline R-Square $\left(R^{2}\right)$ & 0.52 & 0.79 & 0.73 \\
\hline Statistics DW & 0.39 & 0.30 & 0.31 \\
\hline F Statistics & $23.14(<0.001)$ & $57.15(<0.001)$ & $55.27(<0.001)$ \\
\hline Number of observations & 75 & 75 & 75 \\
\hline Number of counries & 5 & 5 & 5 \\
\hline
\end{tabular}


one unit increase in public health expenditure decreases 0.03 units in infant mortality rate and under 5 mortality rate, respectively. Also, 1 unit increase in private health expenditure, respectively, increases 0.02 and 0.014 units in infant mortality rate and under 5 mortality rate.

According to the results of model estimation, the results of all 3 models are significant at the level of 5\%. Furthermore, the F-statistics for all 3 models $(23.14,57.15$ and 55.27 ) indicate the significance of the whole regression model. The obtained coefficient of determination $\left(R^{2}\right)$ for models of this group of countries indicates that the models fit the data well.

\section{Estimation in countries with health systems containing the traditional Sickness insurance}

Based on the results of estimation (Table 3 ) for models 1 , 2 , and 3 at the significance level of 5\%, 1 unit increase (decrease) in public health expenditure leads to 0.5 unit increase (decrease) in life expectancy at birth, and -0.29 and -0.03 unit decrease (increase) in infant mortality rate, and under 5 mortality rate, respectively. Similarly, the results for the impact of private health expenditure on life expectancy at birth, infant mortality rate, and under 5 mortality rate are $0.78,-0.16$, and -0.088 , respectively. Also, according to the results of the models, 1 unit increase (decrease) in per capita income leads to 5.52 unit increase (decrease) in life expectancy at birth, and -1.24 , and -1.11 unit decrease (increase) in infant mortality rate, and under 5 mortality rate, respectively. Furthermore, 1 unit change in the per capita number of physicians leads to $0.05,-0.03,-0.005$ units of change, respectively, in dependent variables in 3 studied models.

Furthermore, the obtained F- statistics in all models indicate the significance of entire regression. The coefficients of determination $\left(\mathrm{R}^{2}\right)$ for these models are $0.67,0.90$, and 0.90 , indicating the high proportion of the variance in the dependent variable that can be predicted from the independent variable.

\section{Estimation of results in countries with national health} services

Based on the results presented in Table 4, all variables are statistically significant at significance level of $5 \%$. In

Table 3. Estimated results in health systems of the countries with traditional sickness insurance

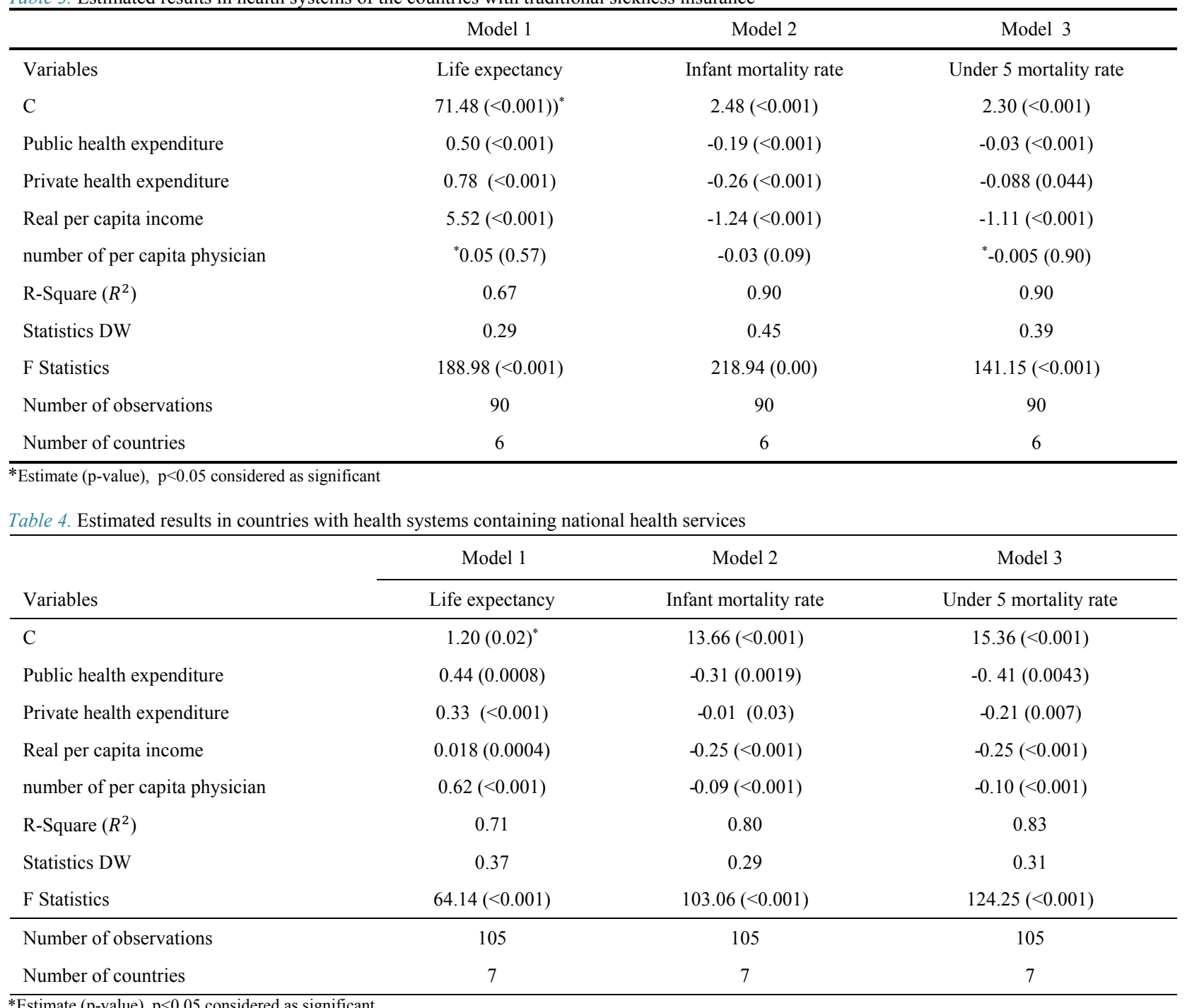




\begin{tabular}{lccc} 
Table 5. Estimated results in countries with mixed health system & \multicolumn{2}{l}{ Model 2 } & Model 3 \\
\cline { 2 - 4 } Variables & Life expectancy & Infant mortality rate & Under 5 mortality rate \\
\hline C & $70.34(<0.001)^{*}$ & $35.97(<0.001)$ & $33.76(<0.001)$ \\
Public health expenditure & $0.006(0.049)$ & $-0.005(0.0002)$ & $-0.01(0.049)$ \\
Private health expenditure & $0.009(<0.001)$ & $-0.003(<0.001)$ & $-0.007(<0.001)$ \\
Real per capita income & $4.01(<0.001)$ & $-0.15(0.028)$ & $-0.28(<0.001)$ \\
number of per capita physician & $0.95(0.01)$ & $-0.46(0.0007)$ & $-0.18(<0.001)$ \\
R-Square ( $\left.\mathrm{R}^{2}\right)$ & 0.78 & 0.82 & 0.79 \\
DW Statistics & 0.34 & 0.35 & 0.31 \\
F Statistics & $115.1(<0.001)$ & $117.69(<0.001)$ & $101.23(<0.001)$ \\
\hline Number of observations & 105 & 105 & 105 \\
Number of countries & 7 & 7 & 7 \\
\hline *Estimate (p-value), $<<0.05$ considered as significant & & & 7 \\
\hline
\end{tabular}

this regard, 1 unit increase (decrease) in public health expenditures leads to 0.034 unit increase (decrease) in life expectancy at birth. Furthermore, 1 unit increase (decrease) in public health expenditure leads to -0.21 and -0.41 units decrease (increase) in infant mortality rate and under 5 mortality rate. On the other hand, 1 unit increase in private health expenditures leads to 0.023 unit increase in life expectancy at birth and -0.81 and -0.31 units decrease in in mortality indicators included in the study. Furthermore, the coefficients of determination $\left(\mathrm{R}^{2}\right)$ for models are $0.83,0.80$, and 0.71 .

\section{Estimation of results in countries with mix health sys-} tems

Based on the obtained results for model 1 in Table 5, one unit increase in public and private health expenditures leads to 0.26 and 0.94 units increase (decrease) in life expectancy at birth, respectively. Furthermore, based on model 2, one unit increase (decrease) in public and private health expenditures leads to -0.52 and -0.43 unit decrease (increase) in infant mortality rates, respectively; the coefficients for impact of these expenditures on under 5 mortality rate based on model 3 are -0.21 and -0.07 . Based on models 1,2 , and 3 , one unit increase (decrease) in per capita income will lead to 4.01 increase (decrease) in life expectancy at birth and -0.15 and -0.28 units decrease (increase) in infant mortality rate and under 5 mortality rate. Also, for the studied models, 1 unit change in per capita number of physicians leads to $0.94,-0.46$, and -0.18 change in dependent indicators, respectively. Coefficients of determination for the studied models indicate that all models have a good fit.

\section{Discussion}

The results showed that among various explanatory variables, health expenditures (public-private) had the most important effect on health outcomes. According to the study results among the 4 panel of countries with different health care systems, increase in the health expenditure has a significant impact on improving health outcomes. The results of the present study are consistent with those of empirical studies performed by several researchers including Berger and Messer (2002) and others (22-25). Furthermore, in countries with mixed health care systems and traditional sickness insurance, the results indicate that private health expenditures have a higher impact on health outcomes than public health expenditures (26). The high level of private health expenditures in these countries is the reason for the profound impact of these expenditures on the health sector. Also, in some studies, the impact of public health expenditures is lower than the private health expenditures, or generally these expenditures are not significant (22). On the other hand, similar to Akinci et al. (2014) and other studies, it has been found that in countries with national health service and those with national health insurance systems, the effect of public health expenditure is higher than the private health expenditure $(12,14,15,27)$, and this is due to the lower responsibility of the private sector compared to the public sector in health.

Furthermore, by comparing the obtained results between the 4 health care systems, it was found that health expenditure (public-private) had a higher impact on health outcomes (life expectancy at birth, infant mortality rate, and under 5 mortality rate) in countries with national health care systems compared to countries with national health insurance systems and other health care systems. These results are also consistent with research by Elola (13). Countries with national health system have higher efficiency than those with national health insurance systems due to the direct control over health expenditure (28), more equal distribution of resources $(29,13)$, less out-of-pocket health expenditure, and less organizational costs (31).

On the other hand, in countries with traditional sickness insurance, health expenditures have higher effects on health outcomes compared to countries with national health insurance and those countries with mix health care system. These results are consistent with Joao's study in which most of the countries with traditional sickness insurance had greater efficiency than countries with national health insurance systems (32). 
Also, in our study, results indicated that health care expenditures had the least impact on health outcomes in countries with mixed system. These results are consistent with those of Asandului's study, which can be implicitly extracted (33).

The study findings revealed a significant impact of per capita income on health outcomes. Moreover, the results revealed that per capita income had more effects on health outcomes compared to health expenditures (public-private). These results are consistent with results of a study by Makuta (15). It is believed that this might be due to the low capacity and inefficiency of existing institutions in the health sector or to the complete substitution between public and private health expenditures (17).

As one of the study's limitations, in this research to investigate the efficiency of health systems, 3 outcomes (life expectancy at the birth, infant mortality rate, under 5 mortality rate) were taken into account, while other parameters such as the health system environment, individual life style in each health care system, and the economic and political status are among the important factors that can be used as dependent variables in further studies to indicate health status.

\section{Conclusion}

The main conclusion of the present study was that in addition to increasing the expenditure in health sector, improving per capita income and access to physician also play significant roles in the health status of the people. Also, according to different impacts of private and public health expenditures on health outcomes in each health care system, in countries with national health service, the public sector should be more responsible for the health of the country . Similarly, in countries with mixed system, the private sector should be more responsible for the health of the country. Therefore, countries should select an appropriate combination of health expenditure based on types of health care systems.

\section{Conflict of Interests}

The authors declare that they have no competing interests.

\section{References}

1. Bayati M, Akbarian R, Kavosi Z. Determinants of Life Expectancy in Eastern Mediterranean Region: A Health Production Function. Int J Health Policy Manag. 2013;1(1):57-61

2. Jaba E, Balan CB, Robu IB. The relationship between life expectancy at birth and health expenditures estimated by a cross-country and timeseries analysis. Procedia Econ and Financ. 2014 Jan 1; 15:108-14.

3. Memarian E. The Relationship between Health Care Expenditure, Life Expectancy and Economic Growth in Iran. J Appl Environ Biol Sci. 2015; 5(10S):284-290.

4. Lalonde M. A New Perspective on the Health of Canadians: A Working Document. Ottawa, Canada: Information Canada; 1975.

5. Scheffler RM. Health expenditure and economic growth: An international perspective. Occasional Papers on Globalization. 2004 Nov; 1(10):1-9.

6. Kalemli-Ozcan S, Ryder HE, Weil DN. Mortality decline, human capital investment, and economic growth. J Dev Econ. 2000 Jun 30;62(1):1-23.

7. Anyanwu JC, Erhijakpor AE. Health expenditures and health outcomes in Africa. Afr Dev Rev. 2009 Sep 1;21(2):400-33
8. Miller G, Roehrig C, Hughes-Cromwick P, Lake C. Quantifying national spending on wellness and prevention. InBeyond Health Insurance: Public Policy to Improve Health. 2008 Oct 13 (pp. 1-24). Emerald Group Publishing Limited.

9. WHO, World health statistics 2015 : http://www.who.int/en/

10. Rajkumar AS, Swaroop V. Public spending and outcomes: Does governance matter? J Dev Econ. 2008 Apr 30; 86(1):96-111.

11. Kim TK, Lane SR. Government health expenditure and public health outcomes: a comparative study among 17 countries and implications for US Health care reform. Am Int J Contemp Res. 2013 Sep; 3(9):813.

12. Akinci F, Hamidi S, Suvankulov F, Akhmedjonov A. Examining the Impact of Health Care Expenditures on Health Outcomes in the Middle East and N. Africa. J Health Care Finance. 2014; 41(1).

13. Elola J, Daponte A, Navarro V. Health indicators and the organization of health care systems in western Europe. Am J Public Health. 1995 October; 85(10): 1397-1401.

14. Novignon J, Olakojo SA, Nonvignon J. The effects of public and private health care expenditure on health status in sub-Saharan Africa: new evidence from panel data analysis. J Health Econ Rev. 2012 Dec $11 ; 2(1): 22$.

15. Makuta I, O'Hare B. Quality of governance, public spending on health and health status in Sub Saharan Africa: a panel data regression analysis. BMC public health. 2015 Sep 21; 15(1):932.

16. Anyanwu JC, Erhijakpor AE. Health expenditures and health outcomes in Africa. Afr Dev Rev. 2009 Sep 1; 21(2):400-33.

17. WB: The World development indicators. In Book the World development indicators: The World Bank; 2016.

18. Karimi I, Salarian A, Anbari Z. A comparative study on equity in access to health services in developed countries and designing a model for Iran. J Arak Uni Med Sci. 2010 Feb 15; 12(4):92-104.

19. Senaratne S. Health Care System Financing Systems: An Inter-Country Comparison. Sri Lankan Journal of Medical Administration. 2013 Mar 26; 14.

20. Baltagi BH, Song SH, Jung BC, Koh W. Testing for serial correlation, spatial autocorrelation and random effects using panel data. J Econometrics. 2007 Sep 30; 140(1):5-1.

21. Cameron AC, Trivedi PK. Microeconometrics: methods and applications. Cambridge university press; 2005 May 9.

22. Berger MC, Messer J. Public financing of health expenditures, insurance, and health outcomes. Appl Econ. 2002 Nov 1; 34(17):2105-13.

23. Halicioglu F. Modeling life expectancy in Turkey. Econ Model. 2011 Sep 30; 28(5):2075-82.

24. Rajkumar AS, Swaroop V. Public spending and outcomes: does governance matter? J Dev Econ. 2008; 86(1):96-111.

25. Baltagi BH, Moscone F, Tosetti E. Medical technology and the production of health care. 2011

26. Crémieux PY, Meilleur MC, Ouellette P, Petit P, Zelder M, Potvin K. Public and private pharmaceutical spending as determinants of health outcomes in Canada. Health Econ. 2005 Feb 1; 14(2):107-16.

27. Rad EH, Vahedi S, Teimourizad A, Esmaeilzadeh F, Hadian M, Pour AT. Comparison of the effects of public and private health expenditures on the health status: a panel data analysis in eastern mediterranean countries. Int J Health Policy Manag. 2013 Aug; 1(2):163.

28. Abel-Smith B. Cost containment and new priorities in the European Community. The Milbank Quarterly. 1992 Jan 1:393-416.

29. JoĖnsson B. What can Americans learn from Europeans?. Health Care Financ R. 1989 Jan 1;11(1):79-93.

30. Evans RG. Public health insurance: the collective purchase of individual care. Health Policy. 1987 Apr 1; 7(2):115-34.

31. Poullier JP. Administrative costs in selected industrialized countries. Health Care Financ R. 1991 Dec;13(4):167-72.

32. Medeiros J, Schwierz C. Efficiency estimates of health care systems. Directorate General Economic and Financial Affairs (DG ECFIN), European Commission; 2015 Jun.

33. Asandului L, Roman M, Fatulescu P. The efficiency of healthcare systems in Europe: A data envelopment analysis approach. Procedia Econ and Financ. 2014 Jan 1;10: 261-8. 